\title{
Possible Methodology for Assessing Latvia’s Integration Process in the European Union
}

\author{
Juris Kanels \\ Transport and Telecommunication Institute, Riga, Republic of Latvia
}

\begin{abstract}
In May 2019, the 15th anniversary of Latvia's membership in the European Union is celebrated. Apart from purely economic results, membership in the European Union undoubtedly also affects the functioning of the state public administration system. The EU encourages to maximise the rational use of human resources, ensure the efficient functioning of institutions, and provide modern, high-quality, and convenient services to the population, while reducing the administrative burden and simplifying the regulatory framework. At the same time, even after 15 years, the assessment of the impact of Latvia's membership in the EU is rather hypothetical, since the evaluation of the actual impact of integration and joining the European Union has been largely fragmented. At this paper, the author focuses on analysing the possible methodology which can be used for assessing Latvia's integration process in the European Union. The impact assessment method has also found its way of being applied to the process of European integration. In the context of this integration, the impact assessment aims to provide with information on the political, economic, social, and environmental impact of implementing the Community policy or certain regulations and directives. The author wants to stress that the EU integration is not the only area where impact assessment method could be applied in the public governance. This method can (and actually is) widely used for evaluation of different public policy strategies and programs. This paper deals with case research using the "comparative research on public management policy" proposed by Michael Barzelay. Its purpose is to understand the changes in public administration policy by using case studies. Barzelay suggests using one of the models - the Kingdon's model, the Baumgartner and Jones's model, or Levitt and March's model allowing one to analyse the public policy-making process.
\end{abstract}

Keywords: public policy analysis, impact assessment, integration in the EU

\section{Introduction}

Assessment of the effectiveness of implemented policies and programs is one of the key elements of good governance. Managers of both private and public organizations need feedback to be able to make optimal decisions about the direction of the future development of the managed organization. Unfortunately, too many managers at national and local level do not get enough information to evaluate possible results and outcomes of the programs to be implemented. Existing information is often fragmented or inadequate for effective decision-making. In addition, particularly the heads of local government organizations are often faced with the following obstacles when evaluating municipal programs:

Juris Kanels, Ph.D. student of Political Science, University of Latvia; Acting Rector, Transport and Telecommunication Institute, Riga, Republic of Latvia. 
- Limited staff and financial resources;

- Limited time period for evaluation;

- The need (or willingness) to use the staff, assigned to make the evaluation of programs, for other operational purposes.

For these and other reasons, use of evaluation of policy strategies and programs in public administration is still often insufficiently planned and superficial (Hatry, Winnie, Fisk, \& Blair, 1981).

The aim of the paper is to explore the use of impact assessment in public administration and to evaluate to what extent it is applicable for assessment of progress of Latvia's integration in the EU. The article proposes the case study method and several models for such practical assessment.

There are several concepts used for public policy analysis, such as policy evaluation, policy research, program evaluation, public administration science, and political science. The differences between these concepts are following:

- Policy evaluation focuses on comparing different public policy alternatives rather than describing or explaining them;

- Policy research involves describing different policies, explaining and evaluating their existence;

- The evaluation of the programs emphasizes the evaluation of specific programs without seeking to formulate the main principles of evaluation;

- Public administration science focuses on the analysis of policy decisions taken by legislators and public administration;

- Political science prioritises systematic research on quantitative or qualitative analytical methods.

In order to consider a public policy analysis to be of high quality, it must be meaningful, justified, credible, original, and enforceable (OECD, 1997).

In all industrially developed countries, policy implementation to a greater or lesser extent is based on specific policy-planning documents. The planning cycle consists of several basic steps: needs assessment, agenda setting, policy development, decision-making and implementation, and policy outcomes assessment (see Figure 1). The policy-making process is characterized by its cyclical nature. Policy-making is an ongoing process, the results of which can be used in the future to develop an improved or customized policy.

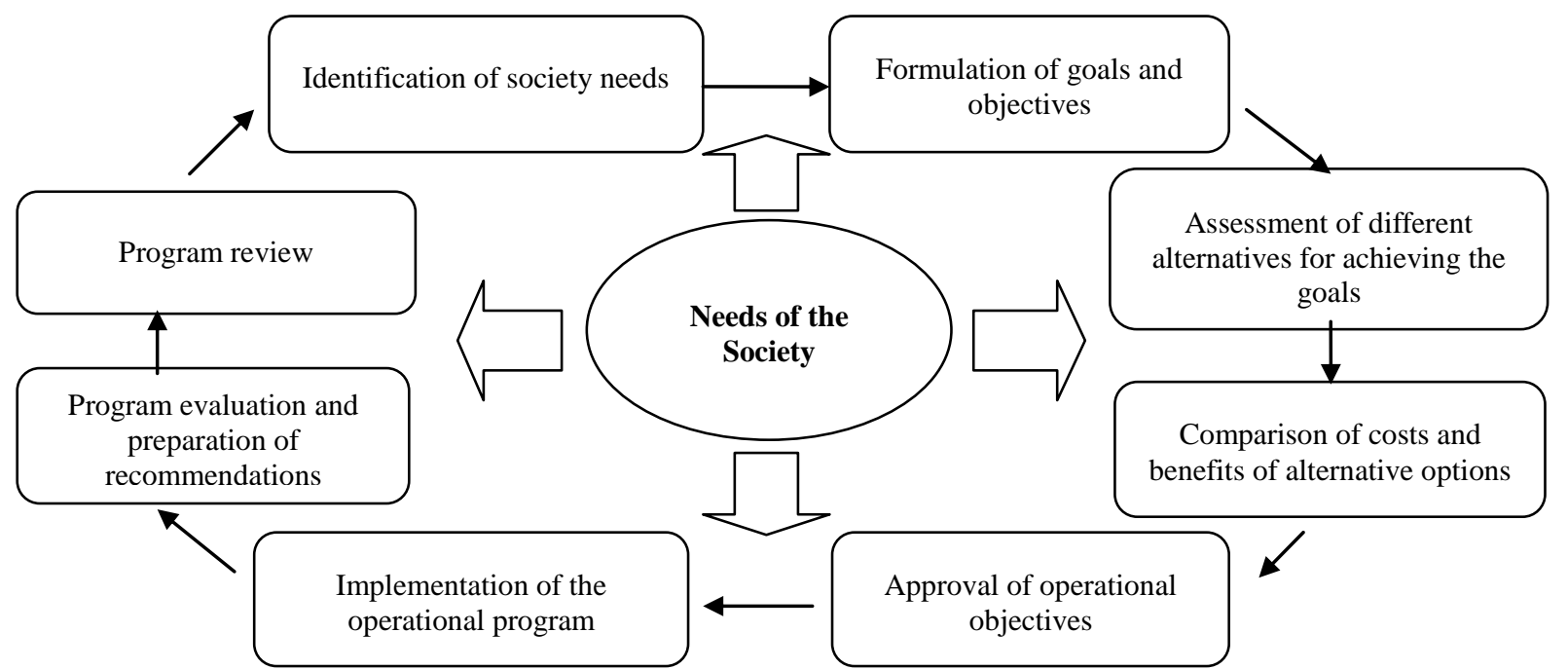

Figure 1. Policy-planning and implementation cycle (Source: Parsons, 2005). 
This planning and implementation cycle is based on the use of active policy evaluation. Stuart S. Nagel (2002) defined public policy analysis as an action to determine which of the possible public or government policy alternatives will best achieve a set of goals. This definition includes five elements of policy evaluation:

(1) Goals, including existing regulatory constraints affecting them;

(2) Policies, programs, projects, decisions, variants, tools, and other alternatives available to achieve goals;

(3) Relationships between policies and objectives, including interactions that have developed intuitively, based on management decisions, through statistics, observation, deduction, assumptions, or other means;

(4) Preliminary conclusions on which policies or a combination of these policies are advisable, taking into account existing objectives, policies, and their interactions;

(5) Conclusions on what should be done to make the other best or other alternative the best alternative.

Peter Dahler-Larsen (2005) had mentioned three possible approaches for assessing public administration, including policy:

(1) Goal-oriented evaluation. It encourages the evaluation of the administration's work, its reforms, and the policies pursued in relation to the goals set by politicians, contained in laws, government decisions, or political statements. However, this is a very unsafe approach, as political decisions are not always consistent and coherent, often including hidden intentions.

(2) Theory-based assessment. This approach advises evaluators to make their own assumptions and use their own criteria to assess the success or failure of public administration. However, such an approach is subjective, as each appraiser can pay more attention to the performance parameters and their significance.

(3) Responsive approach and participatory assessment. The essence of this approach is to identify specific groups of society whose interests are related to some specific results of public administration, to find out what policy evaluation criteria are important for these groups and what importance they attach to the criteria. However, this method is also complex and can be politically manipulated. Therefore, the task of finding the most optimal way to evaluate the performance of public administration and its degree of responsibility is still topical.

\section{Use of the Impact Assessment Method in Public Governance}

The impact assessment is characterised as an important strategic element in the policy-making and administrative management process in order to analyse a priori the possible positive or negative, direct and indirect, and planned and accidental impact on individuals, institutions, or the environment, which will be generated or have been generated by the decisions to be made, actions to be taken or projects to be implemented. ${ }^{1}$ It relates to the main areas of public sector activities-programmes, legislation, and the budget through which the government institutions implement their policies and thus affect the life of society.

This paper focuses on the type of impact assessment based on a combination of facts and values aimed at assessing the impact of the actions performed (interventions). In order to specify the objectives of the policy assessment and to get a clearer idea of the possible results, it is important to determine the most precise criteria for the fulfilment of the task. The assessment criteria determine the values that will be used in the assessment. Many impact assessments use the following criteria recommended by the Development Assistance Committee of the Organisation for Economic Co-operation and Development (OECD-DAC).

\footnotetext{
${ }^{1}$ World Bank, available at: https://ieg.worldbankgroup.org/evaluations.
} 
- Relevance: The extent to which the objectives of the activity performed is suited to the global priorities and policies;

- Effectiveness (usefulness): The extent to which the objectives of the planned activity have been fulfilled or are likely to be fulfilled taking into account their relative importance;

- Efficiency (productivity): Measures taken to turn resources and investments (finances, funds, knowledge, time, equipment, etc.) into results;

- Impact: Positive and negative primary and secondary long-term effects directly or indirectly caused by planned or unforeseen interference;

- Sustainability: The benefit from continuing the activity performed after the completion of the project. The investments must be sustainable, both from an environmental and financial point of view. If the emphasis was not placed on external assistance, then sustainability can be defined as the key stakeholders' ability to sustain the benefits of project implementation after the donor funding is discontinued (OECD-DAC, 2010).

The assessment criteria should be perceived as concepts to be taken into account in the assessment of the social and economic impact of policy measures. In turn, by carrying out an assessment for each of the generally defined criteria, more specific indicators should be identified, coordinating them with the key stakeholders, for example, criteria, and/or standards that are consistent with the type and context of the programme being implemented (Rogers, 2014).

The impact assessment method has also found its way of being applied to the process of European integration. The document "Improving policy instruments through impact assessment" prepared through the Joint Initiative SIGMA of the OECD and European Union states that, in the context of European integration, the impact assessment aims to provide the government and the private sector with information on the political, economic, social, and environmental impact of implementing the Community policy or certain regulations and directives. Ideally, such an assessment should result in quantitative indicators showing the costs of implementing the EU legislation and their impact on national, local government and private sector budgets. However, even if the quantitative information cannot be obtained, qualitative information can still play an important role. For example, it is important to assess the impact of the decisions to be made on the functioning of certain institutions without specifying exactly what the costs of these changes will be. An important thing in itself is the understanding of the problems to be solved, the need for staff training and business continuity (Project SIGMA, 2001).

\section{Case Studies for Analyzing the Changes in Public Governance}

This paper deals with case research using the "comparative research on public management policy" proposed by Michael Barzelay (2001). Its purpose is to understand the changes in public governance policy by using case studies (see Figure 2). 


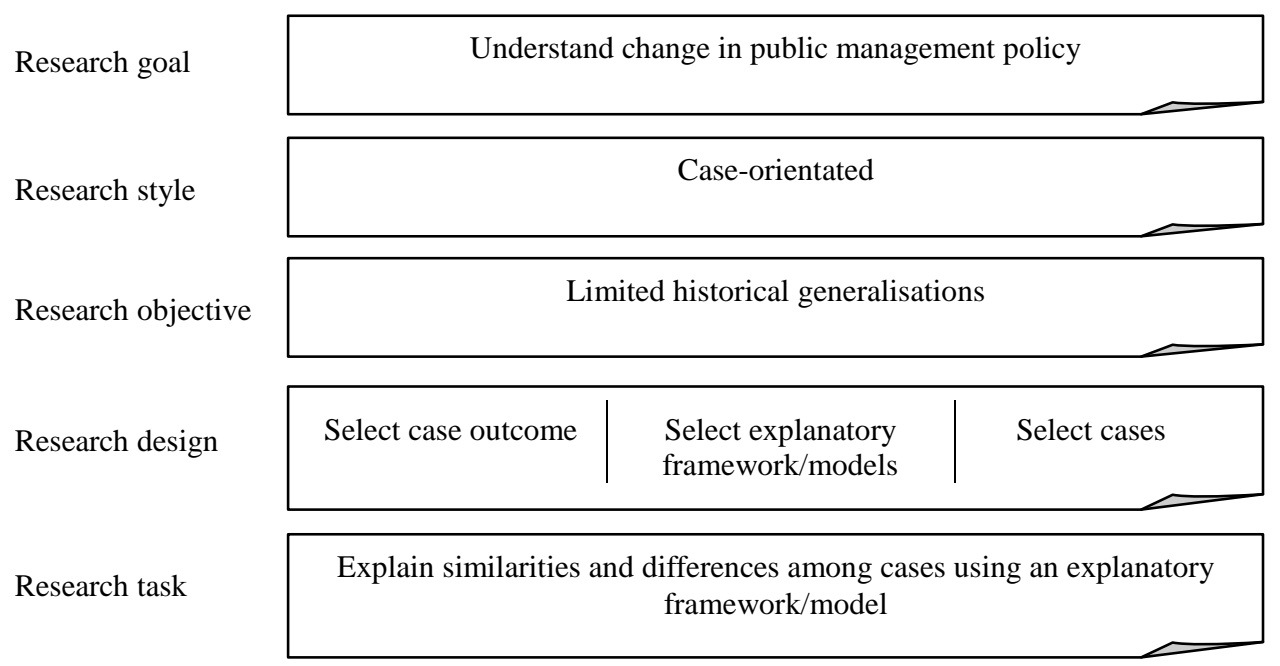

Figure 2. Comparative researches on public management policy.

The determination of the characteristic circumstances or framework is based on procedural models for the adoption of specific policy decisions. These models focus on factors interacting with each other during the course of the activity to explain policy changes depending on the choices made by decision-makers. The main task of using this method is to benchmark the analysed similar cases and to explain their immediate or long-term effects (outcomes) in order to try to understand why the results and consequences of the action are exactly, as they can be effectively identified, and why under similar conditions the consequences are different or vice versa-what these different cases have in common. In particular, with regard to the subject of this paper, the research goal of the analysis is to identify and understand how this methodology could be applied for assessing Latvia's integration process in the European Union.

Barzelay (2001) suggested using one of the models-the Kingdon's model, the Baumgartner and Jones's model, or Levitt and March's model allowing one to analyse the public policy-making process (see Figure 3). 
A. Kingdon's model

B. Baumgartner and Jones' model

C. Levitt and March's model

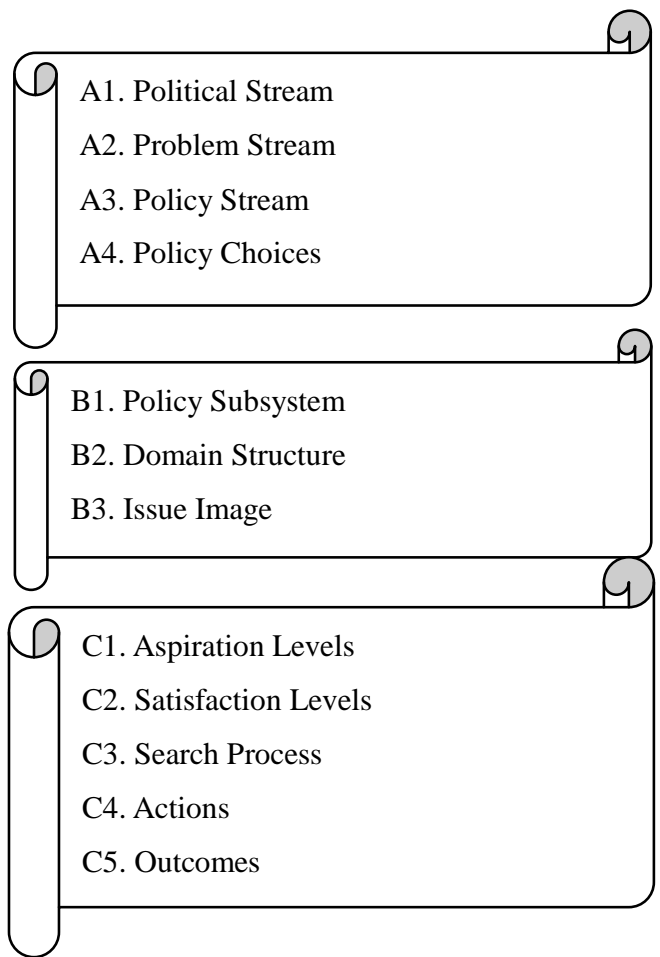

Figure 3. Elements of the explanatory framework (Source: Barzelay, 2001).

The first two of these models are basically focused on analysing public policy-making, while the third is focused on the organisation's ability to learn and change in the policy-making process. To concisely describe each of them, it can be said that John Kingdon's model is a narrative methodology manual that is used to investigate individual (discrete) changes in the policy process, for example, the adoption of a specific law. It can thus be said that the model covers two processes - the definition of the agenda and the study of options for action that can be influenced by many different factors or streams, as John Kingdon calls them.

In turn, Frank R. Baumgartner and Bryan D. Jones's model is focused on reporting the most important changes, which result from implementation of the policy (Baumgartner \& Jones, 2009). These authors believe that there is limited scope for significant changes to the common policy, as long as decisions are made within its subsystems that are relatively stable. Thus, in order to be able to make new decisions on implementation of the policy, it is necessary to undermine the stability of the responsible subsystem-this is the process that is analysed by the relevant model. In this way, the ground for more fundamental policy reforms is provided.

The third, or Barbara Levitt and James G. March's model is orientated towards the organisation's ability to learn in the policy-making process. It is useful for studying the existing stability and changes over a particular period. When the current situation in the administration system is not satisfactory, other more acceptable solutions will be sought out. These quests (learning) can be based on both the experience of your own and other organisations (Barzelay, 2001). In general, the proposed method and models of analysis help to find and explain the differences in national policy in a given field because of using the outcome analysis. 


\section{Application of the Case Study Method to the Integration Process of Latvia in the European Union}

The author recently has made a study, named "Impact of accession to the European Union on the development of transport policy in the Republic of Latvia" where impact assessment method was used. During the preparation of this study, several substantial and structural constraints were felt. First of all, it was a large amount of the information and research materials that had to be processed analyzed the situation in the whole branch of national economy. Therefore, the case study approach is very suitable solution in such circumstances.

Due to this problem in the above mentioned research, direct impact of the European Union on development of transport sector in the Republic of Latvia is presented in the form of specific concrete examples, in which a clear correlation is shown between the adoption of a specific EU-level legislative acts and the consequences of their implementation in the country. For example, there is evidence that the quality of fuel used by motor vehicles in the country has improved significantly while Latvia is in the European Union. In 2004, when Latvia became an EU Member state, the Euro 3 standard fuel was allowed for road transport (with a maximum permissible NOx-nitric oxide value of no more than 5.0). Contrary to that only Euro 6 standard fuel with a maximum 0.46 NOx value is permitted in the EU since 2013. As a result of the implemented measures, the total NOx emissions to the air in Latvia have decreased from $18031.35 \mathrm{t}$ in 2004 to $16451.00 \mathrm{t}$ in 2016. At the same time, the number of newly registered passenger cars in Latvia has increased from 11.2 thousand in 2004 to 16.4 thousand in 2016.

There is another case example. Once a single European aviation market has been established, any Community air carrier is free to set passenger and freight charges and to use any route within the European Union without the need for a permit or authorization. The impact of such market liberalization on the aviation sector in Latvia is direct and very significant. If, in 1999, Riga International Airport served 562,000 passengers, and in 2008 (at the beginning of the liberalization of market)-3,691 million, in 2017, the number of passengers at Riga International Airport reached 6,098 million people. It is also possible to mention other similar examples of the impact of joining the European Union on the development of the Latvian transport sector, but the list of all of them would go beyond the scope of this paper. Therefore, the author has used a case study method in his work to make generalizations and conclusions based on concrete examples.

One of the problems that the author encountered during the preparation of study by analyzing the implementation of the transport policy and its results is not possible to clearly distinguish the consequences of different impact factors. Transport is an open industry, oriented towards international cooperation and common market. Thus, its activities are influenced both by the political and economic decisions taken in the particular countries, in the European Union or other international organizations, as well as they are influenced by the general political situation in the world, by the interests of certain groups of society and the interests of certain people. All of these factors, in general, create mutual interactions that result in concrete political, economic, or social consequences.

Applying the case study method and the three above mentioned models to the integration process of Latvia in the European Union, it is possible to find out following observations about possible assessment methodology:

1. Kingdon's model and the Baumgartner and Johns case study model makes it possible to understand that political decisions taken at the beginning of the 1990s regarding the fundamental change of the political and 
economic system of Latvia and its rapprochement with the Western world, including the European Union, gave a significant impetus to the initiation of the legal, structural, administrative, and other reforms of the country, which were necessary for EU integration. They broke the existing domestic political uncertainty and partial balance situation in Latvia, as well as forced the EU member states to adopt political decisions on Latvia's invitation to the accession negotiations and on Latvia's accession to the European Union itself much earlier than originally planned.

2. The Baumgartner and Johns case study model also helps to understand that Latvia's political and administrative decisions on joining the European Union have been greatly influenced by the actions of other candidate countries, first of all Estonia and Lithuania, and the results of their integration process. Often, Estonia played the role of the most serious external impact factor, when, for example, unilaterally announced in 1994 that it would not impose import duties or other non-tariff barriers on goods produced in European Union countries, but in 1996, when negotiated an Association agreement with the EU, declared that it was ready to implement all the legislative requirements of the European Union without a transitional period.

3. The Levitt and March's case study model helps to understand that, when embarking on the integration process in the European Union, Latvian political and administrative management circles gradually became aware of both the opportunities provided by the EU and the requirements set. It became clear that it was not enough to make political decisions about membership of the European Union as a goal of the political development of the country, but it was necessary to carry out significant and long-lasting multidisciplinary domestic policy to achieve this goal. Therefore, several institutional structures, necessary for the management and organization of integration were established (a European Integration Office was set up subordinated to the Prime Minister, as well as relevant departments in ministries and other public administration institutions), several National Programs for Integration in the EU were approved and implemented, in 1998 Ministry of Foreign Affairs established a special unit for preparation of the EU accession negotiations, which subsequently became a negotiation team, etc. Latvia named integration into the European Union as an internal political priority and showed that it was able to learn during the EU accession process from its own, as well as from the experience of other countries, which ultimately made it relatively quick to become a member of the European Union. It can be said that in the second half of the 1990s, for Latvia was opened a "window of opportunity", which it successfully seized.

\section{Conclusions}

As a result of previous brief analysis, it can be concluded that the case study method and three mentioned models could be applied for qualitative assessment of integration process of Latvia in the European Union. At the same time, the author would like to point out that only one of the three aforementioned models of the public policy-making analysis is not sufficient for assessing this integration process.

Separate elements of each of them could be used to a greater or lesser extent. For example, the Kingdon's model could be applied for the analysis of the aspects of determination of the political agenda in Latvia in relation to joining the EU, but could not be used assessing the possible alternatives, because such alternatives often did not take place in practice. Baumgartner and Jones's model contributes to the analysis by providing an opportunity to use the element of the conflict expansion process (in respect of this research it is the period when Latvia began to prepare for membership of the EU), during which the previous forms and means of policy implementation were discredited (denied), as well as to use the element of creating faith in the necessary future 
structural changes (while being a part of the European Union). In turn, the elements of Levitt and March's model can help to capture the significant policy reforms which have happened in Latvia during the process of joining the European Union and the ability of state administration to learn and to change the organization of its work methods during the process of this integration.

\section{References}

Barzelay, M. (2001). The new public management: Improving research and policy dialogue. California: University of California Press.

Baumgartner, F. R., \& Jones, B. D. (2009). Agendas and instability in American politics. Chicago: University of Chicago Press.

Dahler-Larsen, P. (2005). Evaluation and public management. In E. Ferlie et al. (Eds.), The Oxford handbook of public management. Oxford University Press.

Hatry, H. P., Winnie, R. E., Fisk, D. M., \& Blair, L. H. (1981). Practical program evaluation for state and local government officials (2nd ed.). Washington D. C.: Urban Institute.

Nagel, S. S. (Ed.). (2002). Handbook of public policy evaluation. Thousand Oaks, California: Sage Publications Inc.

OECD. (1997). In search of results: Performance measurement practices. Paris: PUMA.

OECD-DAC. (2010). Glossary of key terms in evaluation and results based management. Retrieved from http://www.oecd.org/development/peer-reviews/2754804.pdf

Parsons, W. (2005). Public policy: An introduction to the theory and practice of policy analysis. Cheltenham: Edward Elgar Publishing Ltd.

Project SIGMA. (2001). Improving policy instruments through impact assessment. Paper No. 31. Retrieved from http://www.oecd.org/officialdocuments/publicdisplaydocumentpdf/?doclanguage=en\&cote=ccnm/sigma/puma(2001)1

Rogers, P. (2014). Overview of impact evaluation, methodological briefs: Impact evaluation 1. Florence: UNICEF Office of Research. 